International Journal of English Language and Literature Studies

$\operatorname{ISSN}(e): \quad 2306-0646$

$\operatorname{ISSN}(p): \quad 2306-9910$

DOI: 10.18488/journal.23.2021.102.132.144

Vol. 10, No. 2, 132.144.

(C) 2021 AESS Publications. All Rights Reserved.

URL: www.aessweb.com

check for
updates

\title{
UTILIZING SOCIAL MEDIA NETWORKS AS LEARNING TOOLS FOR FOREIGN LANGUAGES AMONG ARAB YOUTH IN UAE
}

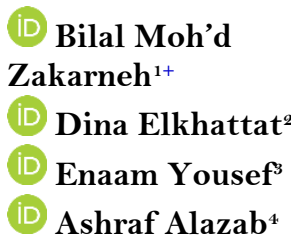

\author{
'Associate Professor, Department of Foreign Languages, College of \\ Humanities and Sciences, Ajman University, UAE. \\ Email:b.ibrahim@ajman.ac.ae Tel:+971506499640 \\ 'Assistant Professor, College of Mass Communication, Ajman University, \\ UAE and Assistant professor in Media and Mass Communication \\ Department, Faculty of Arts, Ain Shams University, Egypt. \\ Email:d.elkhattat@ajman.ac.ae Tel.971543270832 \\ ${ }^{3}$ Assistant Professor, Department of Sociology, College of Humanities and \\ Sciences, Ajman University, UAE and Assistant Professor at the Department \\ of Sociology, Faculty of Arts, Ain Shams University, Egypt. \\ Email: e.youssef@ajman.ac.ae Tel: +971554358596 \\ 'Associate Professor, Department of Sociology, College of Humanities and \\ Sciences, Ajman University, UAE and Professor of Rural Sociology, \\ Kafrelsheikh University, Egypt. \\ Email:asifazab@yahoo.com Tel: +971562138183
}

Th) Check for updates

\section{.}

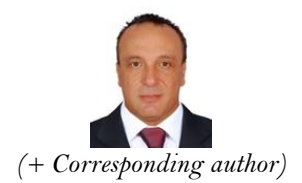

(+ Corresponding author)

thent




\section{INTRODUCTION}

Within the globalized technological world, social media networks such as Facebook, Twitter, Orkut, Myspace, YouTube, Skype, and other social networking sites have become popular information sharing platforms used extensively for communication purposes. One of the key advantages associated with social media is the facilitation of online sharing of knowledge and information among the different groups of people (Baruah, 2012). Indeed, researchers have given great attention to web-based learning facilitation and tools; and reasons informing the increased use of social media networks in learning processes and the use of social media sites as a learning platform that facilitate learners' experience in learning new knowledge and languages (Mc Dermott, 2013; Mondahl, Rasmussen, \& Razmerita, 2009; Spaniol, Li, Klamma, \& Lau, 2009; Stevenson \& Liu, 2013; Tosh \& Werdmuller, 2004).

For example, Megan and Liu (2010) assessed whether three foreign language learning websites incorporating Web 2.0 tools met the goals and needs of current and potential language learners. Megan and Liu (2010) also explored the pedagogical and technical usability of these sites. Results showed that increased user interest in traditional Web 1.0 learning technology was largely contributed by their use of social networks as platforms for learning a language. Increased users' interest in these sites was also contributed by their desire to learn specific reading and writing skills by using tutorials and readings which are facilitated through these sites. Supporting this view, Mondahl et al. (2009) noted that teachers and students alike were more motivated to learn language when using the electronic learning platform than traditional case-based learning system. The results also showed that students in the treatment group were more successful in solving assignment problems than the control group and the control group was more successful at the linguistic level, i.e., solving problems of syntax and morphology. Elsewhere, Fuchs et al. (2010) provides a theoretical understanding of these notions through a web model technosocial system that enhances human cognition towards communication and co-operation.

Other studies have focused on Arab learners' use of social media sites as learning platforms and features of these social media sites that make them appropriate for learning language (Baird \& Fisher, 2005; Griesemer, 2012; Mc Dermott, 2013; Spaniol et al., 2009; Tosh \& Werdmuller, 2004). For example, Mc Dermott (2013) attributes the increased use of social media sites as learning platforms among Arab students to the advent of smartphones, tablet computers and Wi-Fi in most Arabian countries. According to Mc Dermott (2013), smartphones, tablet computers and Wi-Fi have enabled students to stay connected and share their learning experience in their network. Mc Dermott (2013) further argues that these technologies enabled Arab youth to access a range of smart devices and use them to learn foreign languages.

Other studies have documented the common social media platforms used by Arab learners of language. For example, Tosh and Werdmuller (2004) identified Web logs as the most common user-friendly means through which the youth learned foreign languages. According to Tosh and Werdmuller (2004) these logs provide an opportunity for learners to connect with members of other learning communities and offer a platform for sharing ideas with their peers. Supporting this view, Spaniol et al. (2009) acknowledged that many Arab youth are currently relying on blogs because they can create them for free and they do not require moderation. Blogs also allow users to create different accounts and use them to follow each other thus facilitating the development of language skills (Spaniol et al., 2009). Mondahl and Razmerita (2014) in a study by El-Emran and Al-Qaysi (2017), it was revealed that Arab students in Oman use social networks as platforms for code-switching while learning a foreign language. However, unlike the present study, in which Facebook, Instagram, and Snapchat are featured as the most used social media learning platforms, El-Emran and Al-Qaysi (2017) identified WhatsApp as the most social networking App used by students and educators to code-switch in Oman. Within the Saudi context, Alaa (2015) investigated the perception of Saudi Female undergraduate students towards the use of social media as a learning tool and revealed that students had a positive attitude towards the use of social media for educational purposes. The results of this study noted that when used for e-learning purposes, social media can improve the quality of education by fostering 
collaboration among learners; facilitates self-directing intentional learning; provides a student-friendly learning environment; and provides learners with highly intensive and peer collaboration opportunity and allows for asynchronous communication.

\subsection{The Importance of Language in Social Communication}

Language has been identified as means of communication among members of a society, and as the basic tool for sharing ideas. Chiu, Krauss, Lam, and Tong (1995) identify language as an integral part of the culture of societies, as well as a component of any particular society. Language pervades social life; it is the principal means for the transmission of cultural knowledge, and the primary means by which we gain access to what is in others' minds. Language is implicated in most of the phenomena that lie at the core of social psychology: attitude change, social perception, personal identity, social interaction, intergroup bias and stereotyping, attribution, and so on (Chiu et al. (1995)

Chiu et al. (1995) summarized the relation of language use cognition and culture in five propositions:

1) The grammatical structure of a language is not sufficient to affect its speakers' ways of thinking.

2) The internal representations evoked or created by language use can affect a language user's subsequent cognitions.

3) Using language to represent a state of affairs can evoke or create an internal representation that differs from the internal representations of the same state of affairs evoked or created by other means of encoding.

4) The form that a linguistic representation takes will be affected by the contexts of language use, including the ground rules and assumptions that govern usage, audience design and the immediate, ongoing and emerging properties of the communication situation.

5) Through communication, the private cognition of individuals can be made public and directed toward a shared representation of the referent. This view links language use to the emergence of social representations or socially shared cognitions, which are core elements of the cultural meaning systems (Chiu et al., 1995). This comes in light of the role and nature of social media as a tool for human contact, awareness-raising, rapid dissemination of knowledge, refinement of cultures and self-expression.

\section{METHODOLOGY}

This study used a mixed method involving the quantitative and qualitative paradigms. A method that allowed for the collection of both quantitative and qualitative data was used to collect numerical data and qualitative data. A survey questionnaire involving open-ended and close-ended questions was used as a data collection tool to collect data on the usage of social media networks as language learning platforms among Arab students. It also collected data on the characteristics, usage, and attitudes of the Arab youth towards the social media networks as a learning platform for learning foreign languages. Specifically, data was collected using an e-survey (an electronic questionnaire) from 400 Arab youth who frequently used the social media networks. These participants were sampled from different Arab countries but living in the United Arab Emirates (UAE). The survey questionnaire also contained open-ended and closed-ended questions on usability and usefulness of this E-learning tool from the perspectives of Arab youth.

The E-questionnaire with open-ended and closed-ended questions enabled researchers to collect quantitative data and qualitative data. It consisted of five parts. The first covered the general information about the sample reflecting characteristics and demographic elements of participants. The second part covered general information concerning language proficiency level of the sample. The third part of the questionnaire covered the usability and preferences of social media networks as a learning tool among the Arab youth. The fourth part focused on assessing attitude of the Arab youth toward the social media networks as a learning platform for learning languages. The last section of the questionnaire contained questions on the influence of social media networks on the uses of languages 
in day- to- day life. Researchers sent a copy of the questionnaire to a number of faculty staff reviewers, and some changes were made in order to apply the pre- test.

A pilot study was conducted in order to evaluate the study's feasibility and improve on the study design prior to implementing a full-scale research project. It also helped to evaluate the validity of the survey questionnaire in line with its purposes. The pilot study involved 40 participants; These participants were asked to indicate their choices and views toward all questions around the use of the social media as a learning platform for collaborative learning, and asked to specify their attitudes toward a Likert scale consisting of five-point scale ranging from 'strongly agree' to "strongly disagree".

\subsection{Objectives of the Study}

Two objectives guided the present study:

1. To assess and analyze the usability, usefulness, and the impact of social media networks as a learning tool for Arab youth.

2. To determine the attitudes of Arab youth towards social media networks as a learning tool for foreign languages.

\subsection{Research Questions}

This study responded to the following research questions:

1. What is the usability, usefulness, and impact of social media networks as learning tools for Arab youth?

2. What are the attitudes of the Arab youth toward social media networks as learning tools for foreign languages?

\section{RESULTS}

3.1. Sample Characteristics

A- Demographics: Gender

Based on gender representation, majority of participants surveyed were female students $(81.25 \%)$ and male $(18.75 \%)$ of the sample. The male students disliked participation in researches and were less motivated to respond to study questions. On the contrary, female participants were motivated to participate in the study and shared the link with others via social media, suggesting that females were more sociable and collaborative than male participants Figure 1.

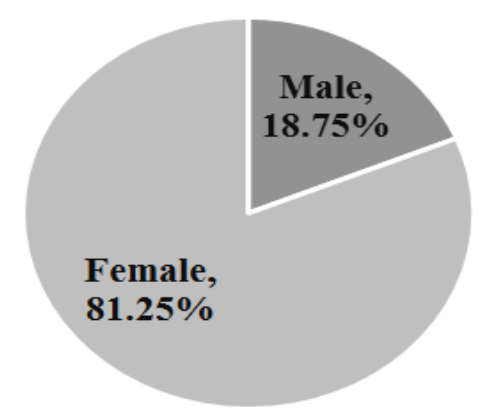

Figure-1. Participant gender representation.

\section{B. Demographics Age}

As can be inferred from Figure 2, a majority (62.75\%) of participants were aged between 18 and 24. Others $(34.75 \%)$ were aged above 24 . This reflects the view by researchers as documented in the extent literature that youth in the age range of 18-24 years tend to use electronic apps and social networks frequently and that they often used them with a view to developing their skills for study and work purposes. This may help in explaining their 
high representation in this study considering the study captures their interests. On the contrary, the low representation by those aged above 24 may be due to their engagement in work-related activities and obligations. Arguably, their low participation may be explained by the notion that they had already developed their language skills for continuing post-graduate studies or for improving their language for better communication at work arena as well and as such they deemed it unnecessary to participate.

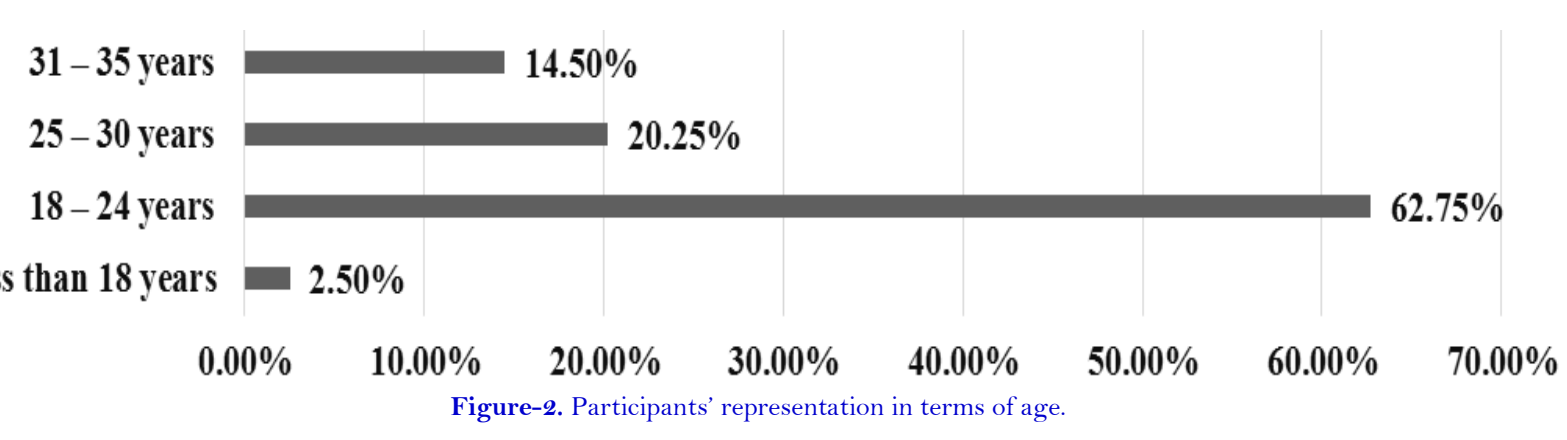

C. Demographic: Education

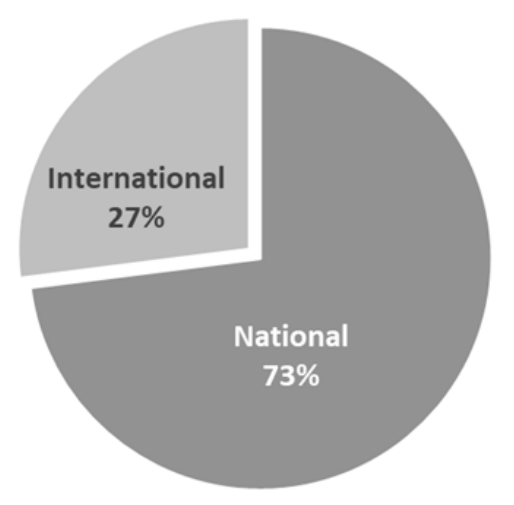

Figure-3. Participants' representation based on educational system.

As shown in Figure 3 and 4, the majority (73\%) of participants had gone through national educational system. Others $(27 \%)$ acquired international educational through the international education programs. University students constituted the largest (62.25\%) proportion of participants followed by secondary school students, university graduates, and postgraduates. A majority $(70 \%)$ of participators were students' either at secondary schools or at universities. As such, it captured the real participants who were the target of the present study: Arab youth, who seek to improve their language skills through creative solutions and electronic tools. The educational system of these students depends on the Arabic language as their mother tongue.

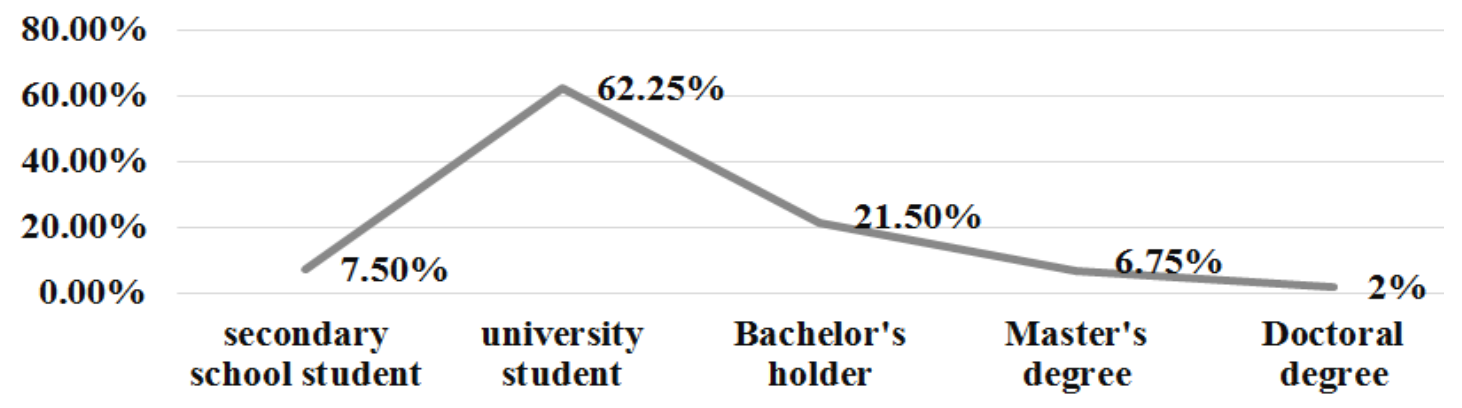

Figure-4. Participant's Educational levels. 


\section{Demographic: Nationality}

Participants varied in their nationality as more than 15 nationalities from the Gulf region and other Arab countries were represented in the sample. This reflects the demographic nature of UAE as it is characterized by people from different countries and nationalities. However, the majority of participants (57.75\%) were from the Gulf region distributed as follows: Emirati nationals (48.5\%), Levant (36\%) and others (6.25\%). Collectively participants from Levant constituted $36 \%$ of the sample. These includes Syrians, Lebanese, Jordanians, and Palestinians while participants from other nationalities, including Egypt, Sudan, Libya, and other Arab countries constituted $6.25 \%$ of the sample (Figure 5).

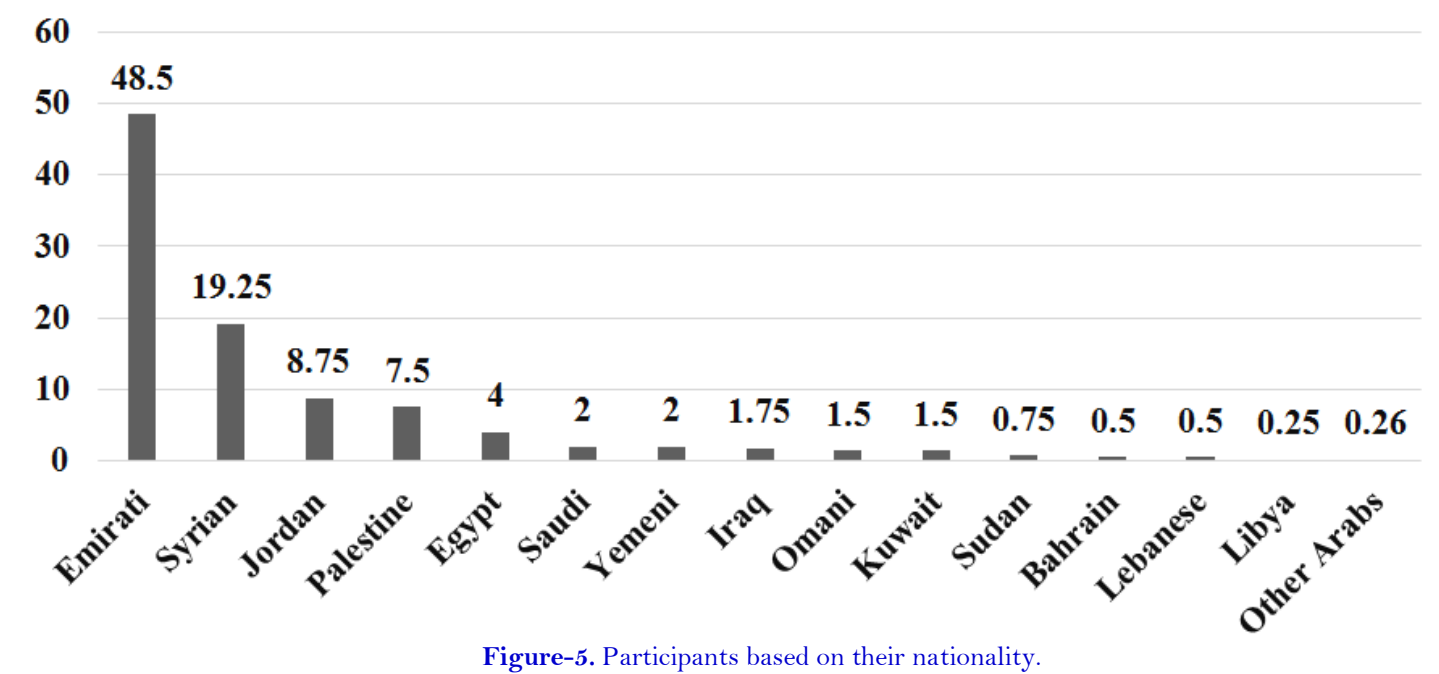

\section{E. Demographic: Socioeconomic Level}

As can be inferred from Figure 6, a majority (45.25\%) of participants was from socio-economically affluent households and majority had an average family income ranging between 15.000 AED and 20. O0O AED. The medium group constituting 27\% had family income ranging between 7.000 AED and 15.000 AED while the lowlevel group constituting $27.75 \%$ of the sample had a family income ranging between 3.000 AED and 7.000 AED. This suggested that a majority of Gulf nationals and others from other nationalities had a high standard of living.

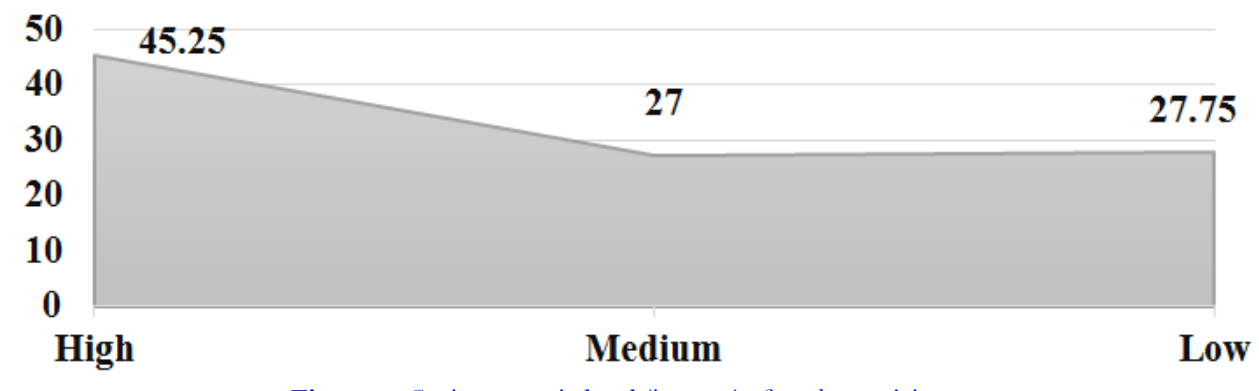

Figure-6. Socioeconomic level (income) of study participants.

\subsection{Arab Touth's Language Proficiency}

\section{A. Main Language for Communication}

A Majority (91\%) of participants were native speakers of the Arabic language. Other participants constituting $9 \%$ of the sample were native speakers of English, French, German and other languages (Figure 7). This was a true reflection of the UAE society, which is dominated by native speakers of the Arabic language and that it harbors Arabs from other Arabic speaking countries. 


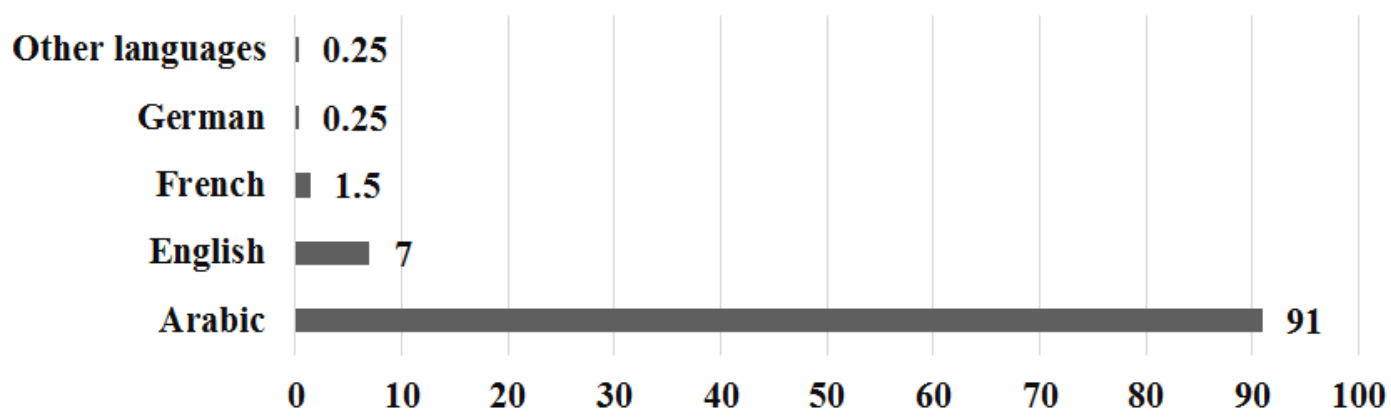

Figure-7. Participants' representation based on their first language.

\section{B. Languages Proficiency Levels}

The participants' responses towards proficiency revealed variation in proficiency of all languages. The percentage of the superior level in all languages except Arabic (51\%) was low with other languages averaging between (3 to 7\%); which means that there is really the need to improve their language skills. Moreover, the results in (Table 1) show that the languages proficiency of all languages except for Arabic and English is very low; the participants expressed their ignorance about many foreign languages with high percentages, and the average was between (65 to $78 \%)$.

Table-1. Participants' representation based on their languages proficiency.

\begin{tabular}{|c|c|c|c|c|c|c|c|c|}
\hline No. & 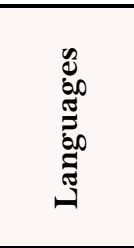 & 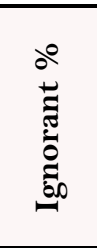 & 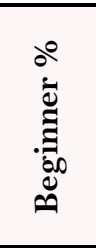 & 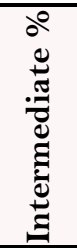 & 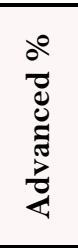 & 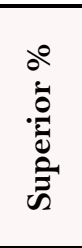 & 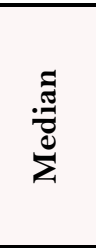 & 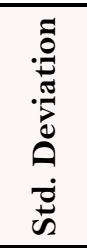 \\
\hline 1 & Arabic & 13.75 & 6.25 & 15 & 14 & 51 & 14 & 17.68 \\
\hline 2 & English & 9 & 19.75 & 40.3 & 23.8 & 7.25 & 19.75 & 13.3 \\
\hline 3 & French & 65.25 & 20.5 & 8.25 & 3 & 3 & 8.25 & 26.29 \\
\hline 4 & German & 75.5 & 11.75 & 5.5 & 3.75 & 3.5 & 5.5 & 31.2 \\
\hline 5 & Spanish & 77.75 & 10.5 & 5 & 3.25 & 3.5 & 5 & 32.42 \\
\hline 6 & Italian & 77.75 & 10.25 & 5.5 & 2.75 & 3.75 & 5.5 & 32.41 \\
\hline 7 & Urdu & 74.75 & 10.75 & 7.25 & 3.25 & 4 & 7.25 & 30.75 \\
\hline 8 & Hindi & 73.25 & 12.25 & 6.75 & 2.5 & 5.25 & 6.75 & 29.98 \\
\hline
\end{tabular}

\subsection{Arab Youth Experiences on Social Media Networks}

\section{A. Years of Experience in Using Social Media}

As it can be seen from Figure 8, participants used social media networks for an extended period. The majority (97\%) reported using social networking sites for long durations. Of these $57 \%$ reported to have used social networking sites for a period extending 4 to 9 years while $34.50 \%$ reported to have been using social networking sites for a period extending 10 to 13 years (Figure 8). This result suggests that these networks can be a useful learning tool for the youth.

\section{B. Participants' Proficiency in Using Social Media Networks}

As demonstrated in Figure 9, collectively an overwhelming majority (86\%) of participants were found proficient in using social media networks. A majority of participants identified their levels of proficiency as intermediate level (27.75\%), advanced level (35.25\%), or superior levels of proficiency (23\%) (Figure 9). This seems logical considering the confirmation herein that participants had used the social media networking sites for an 
extended period. It also suggests that most of participant may be comfortable using social media networks. This may affect their preferences towards using these sites for the purpose of learning languages.

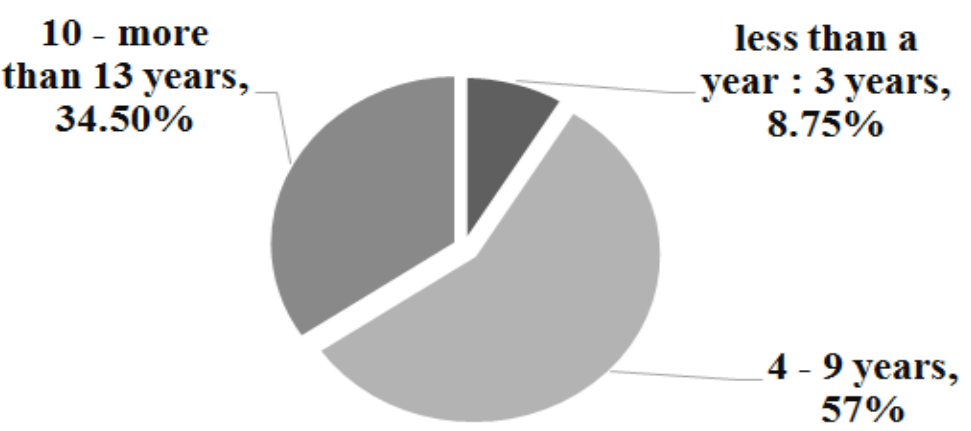

Figure-8. Participants experience with the use of social media networks.

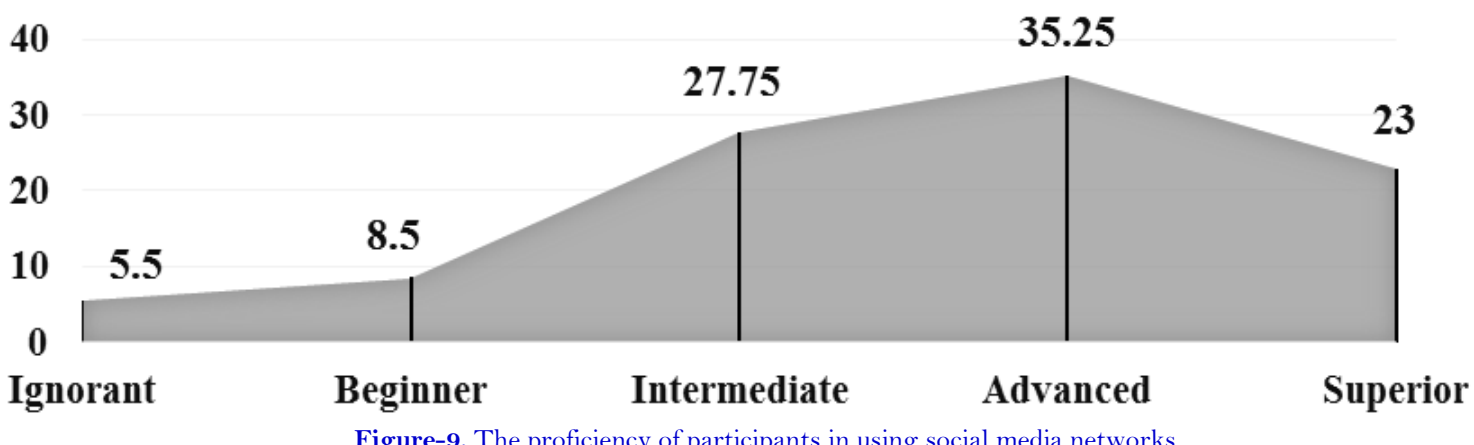

\section{Usability}

Figure 10 reflects that a majority of participants favor the use of social media networks as a learning tool for learning languages and refer to them as a usable tool. The response percentage ranged between high and moderate (option 3 to 5 ) collectively to $78.25 \%$ suggesting that networking sites are useful as learning tools among Arab learners and that they feel comfortable using them for learning purposes. However, a small percentage $(21.75 \%$. option 1 and 2) of participants expressed their reservations towards the use of social media sites as learning tools showing that they disliked in totality the idea of using social media networks as learning tools and that they were not comfortable for them in the learning platform. These participants preferred limiting the use of social media networks for communication purposes rather than for learning, languages Figure 10.

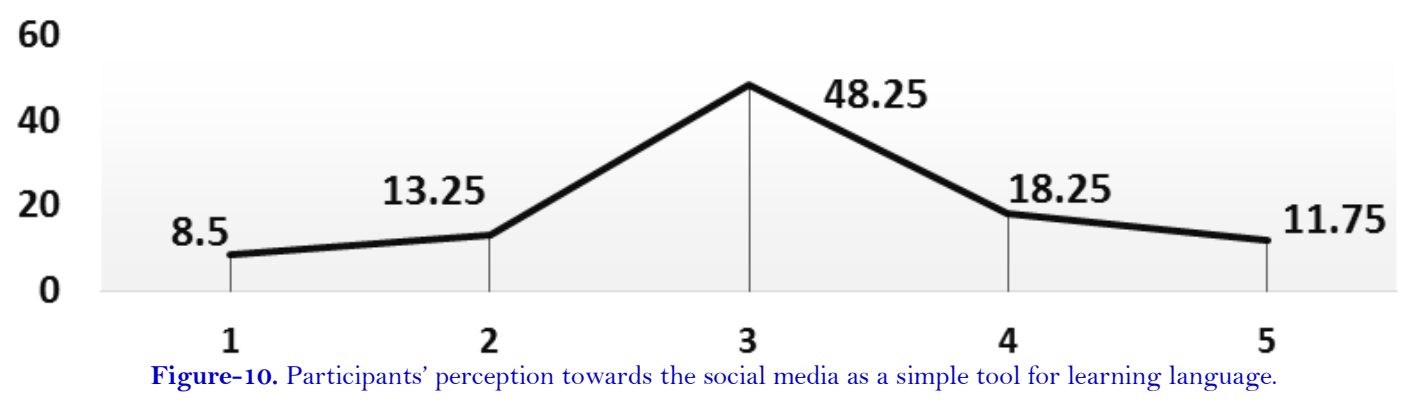

\section{Favorite Tools for Learning Languages}

By recognizing the contrary view, participants were presented with a list of tools and asked to identify those they deemed fit for learning languages. Consistent with the previous responses, a majority (27\%) of respondents identified social media networks as a tool to communicate with others, followed by (26\%) and (22.3\%) respondents who found social media networks useful for learning specialized courses and online courses respectively (Figure 11). 
This result emphasizes that the Arab users use these networks to improve their language skills not only to communicate with others but also to take specialized courses in learning languages both online or offline.

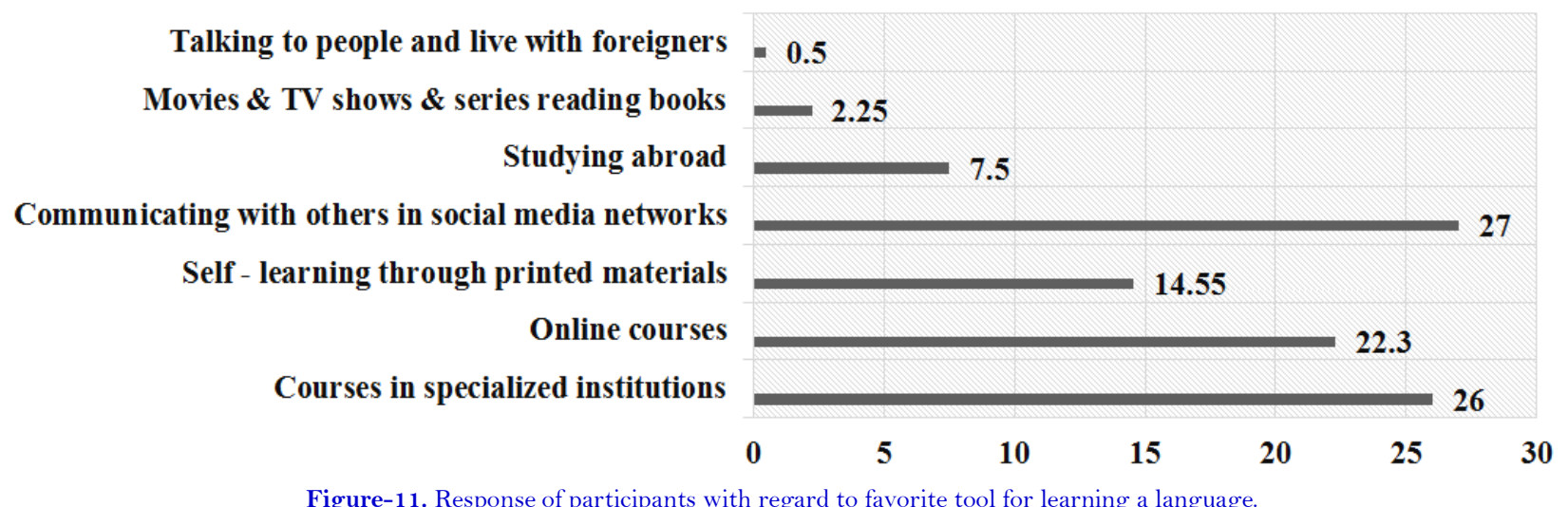

\section{E. Favorite Social Media Network}

With a majority of respondents identifying social media networks as their favorite learning tools, it was important to identify the specific social media network, preferred and commonly used for social learning in UAE. Responses to this question favored Snap chat, identified as the most favorite by $32.25 \%$ of participants; followed by Facebook (21\%) and Instagram (19.50\%) (Figure 12). Though speculative, it is possible to conclude that their preference towards Snap Chat platform may be chosen by its ease of use, and its proficiency while interacting with native speakers.

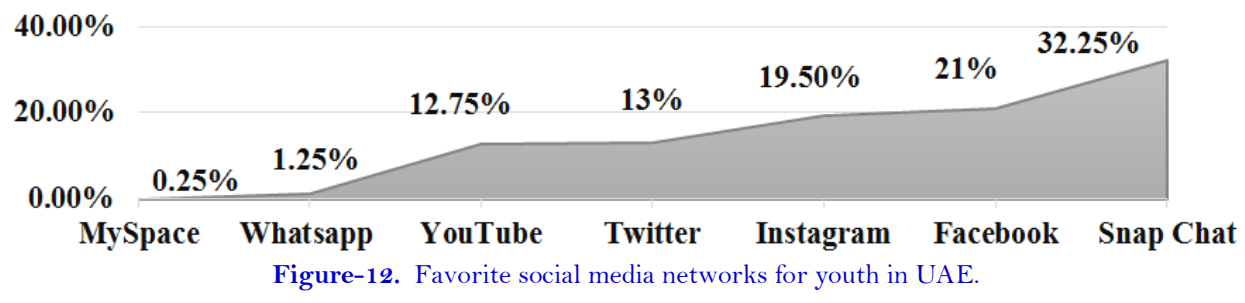

\section{F. Favorite Learning Language Tools in Social Media Networks}

Participants were further asked to identify the favorite learning tools in social media networks (Figure 13). The majority (62.25\%) reported that they learnt languages through chatting and communication with others and that social media networks gave them the ability to interact with other foreigners from different nationalities worldwide. Perhaps participants' preference towards social media as a language learning tool may have been inspired by the idea that it allows them to learn, socialize, and gain knowledge from other partners in communication process through writing, chatting, and exchanging other materials, which may help them gain during the learning process. When we interpret this result in line with the previous results and according to the nature and characteristics of the sample, we can summarize that youth in general like learning through entertaining as an attracting learning tool.

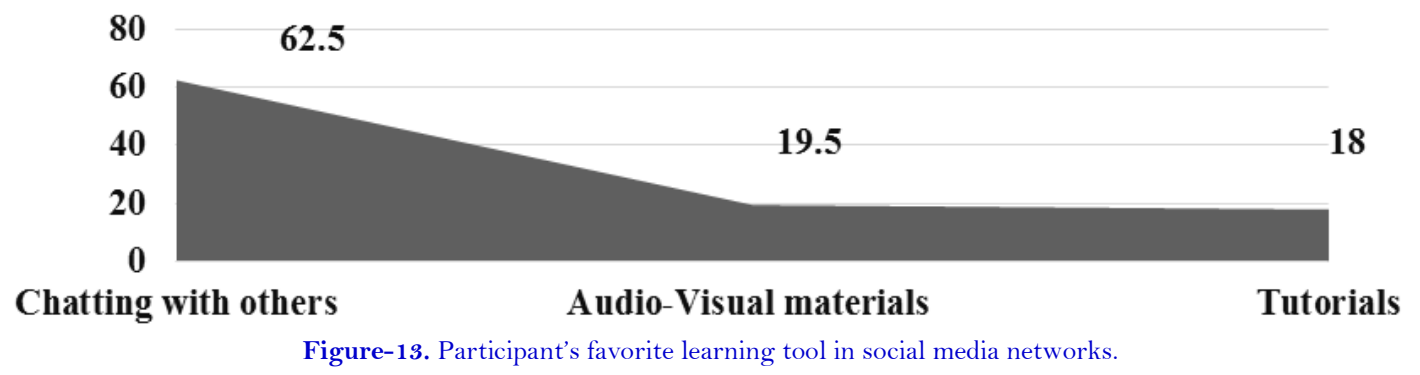




\section{G. Participant's Attitudes towards Social Media as a Learning Tool}

Based on the assessment of the attitudes of the youth toward the social media networks as a learning tool, it was noted (Table 2) that in general youth have a positive attitude towards the use of social media as a languagelearning tool.

Table-2. Participant's attitudes towards social media as a learning tool.

\begin{tabular}{|c|c|c|c|c|c|c|c|c|}
\hline No & Statements & 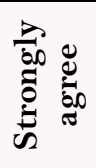 & 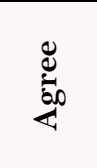 & Z & 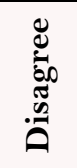 & 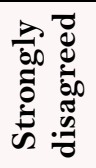 & 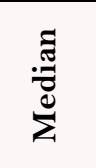 & 旅 \\
\hline 1. & $\begin{array}{l}\text { Social media improves the foreign } \\
\text { language proficiency for their users. }\end{array}$ & 36 & 46.25 & 15 & 1.5 & 1.25 & 15 & 20.4 \\
\hline 2. & $\begin{array}{l}\text { Using social media in learning } \\
\text { languages is fun and full of pedagogical } \\
\text { values. }\end{array}$ & 33 & 44.25 & 19.5 & 1.75 & 1.5 & 19.5 & 18.9 \\
\hline 3. & $\begin{array}{l}\text { I use social media as a means of learning } \\
\text { a foreign language. }\end{array}$ & 26.25 & 44.25 & 23.75 & 4.25 & 1.5 & 23.75 & 17.5 \\
\hline 4. & $\begin{array}{l}\text { I have an interest in } \\
\text { reading/watching/listening to any } \\
\text { content related to the learning of foreign } \\
\text { languages on social media. }\end{array}$ & 29.25 & 42.5 & 22.5 & 4 & 1.75 & 22.5 & 17.2 \\
\hline 5. & $\begin{array}{l}\text { Social media are highly motivating and } \\
\text { entertaining way of learning languages. }\end{array}$ & 27.75 & 47 & 20.5 & 3.25 & 1.5 & 20.5 & 18.8 \\
\hline 6. & $\begin{array}{l}\text { Using a foreign language on social } \\
\text { media helps me to know new cultures. }\end{array}$ & 32.25 & 45.25 & 18.25 & 3.25 & 1 & 18.25 & 18.9 \\
\hline 7. & $\begin{array}{l}\text { I recommend Social media to languages' } \\
\text { learners to develop their writing skills. }\end{array}$ & 32.75 & 43.5 & 18 & 4.5 & 1.25 & 18 & 18.1 \\
\hline 8. & $\begin{array}{l}\text { I recommend Social media to languages' } \\
\text { learners to develop their reading skills. }\end{array}$ & 31.25 & 45.8 & 19 & 3.25 & 0.75 & 19 & 19 \\
\hline 9. & $\begin{array}{l}\text { I recommend Social media to languages' } \\
\text { learners to develop their speaking skills. }\end{array}$ & 28.5 & 47.3 & 19.8 & 3.75 & 0.75 & 19.8 & 19.1 \\
\hline 10. & $\begin{array}{l}\text { I recommend Social media to languages' } \\
\text { learners to develop their listening skills. }\end{array}$ & 32.75 & 45.8 & 18.5 & 1.75 & 1.25 & 18.5 & 19.5 \\
\hline 11. & $\begin{array}{l}\text { I recommend Social media to languages' } \\
\text { learners to develop their vocabulary. }\end{array}$ & 30.75 & 43 & 22.5 & 2.75 & 1 & 22.5 & 18.1 \\
\hline 12. & $\begin{array}{l}\text { I recommend learners of foreign } \\
\text { languages to train themselves on Social } \\
\text { media to develop their Grammar. }\end{array}$ & 27.5 & 39.3 & 25.5 & 5 & 2.75 & 25 & 15.7 \\
\hline 13. & $\begin{array}{l}\text { I recommend learners of foreign } \\
\text { languages to train themselves on Social } \\
\text { media. }\end{array}$ & 29.5 & 43 & 22.5 & 3.75 & 1.25 & 22.5 & 17.6 \\
\hline 14. & $\begin{array}{l}\text { Social media should be an essential part } \\
\text { of the English language teaching. }\end{array}$ & 28.25 & 42.3 & 24.5 & 4 & 1 & 24.5 & 17.3 \\
\hline 15. & $\begin{array}{l}\text { I recommend anyone to } \\
\text { follow/subscribe to the } \\
\text { pages/accounts/channels specialized in } \\
\text { teaching foreign languages because I get } \\
\text { benefited. }\end{array}$ & 32 & 43 & 21 & 2.75 & 1.25 & 21 & 18.2 \\
\hline
\end{tabular}

It was noted that majority of the respondents found social media to be helpful in improving both their skills and knowledge. They either agreed or strongly agreed towards questions regarding the use of social media networks for learning language. Worth noting was that most of respondents showed the willingness to recommend the social 
media to others on account that it could help them benefit in various aspects, including writing, listening, talking and other areas. The argument was that social media networks have a variety of options in addition to the specialized pages for learning languages.

As can be inferred from Table-2, an overwhelming majority (81.25\%) of Arab youth (32.75\%-strongly agree and $43.5 \%$-agree) find social media sites as useful and important in developing their writing skills. The majority of youth (77.05\%) (45.8\%-agree, $31.25 \%$ - strongly agree) find social media sites as useful in developing reading skills. Equally, youth find social media sites as useful in impacting listening skills development (32.75\%-strongly agree, 45.8\%-agree), developing grammar (27.5\%-strongly agree, 39.3\%-agree), vocabulary (30.75\%-strongly agree, 43\%agree). This is in addition to emphasizing the usefulness of social media as a tool of training for foreign language learning and the mastery of interaction with $43 \%$ agreeing, while $29.5 \%$ strongly agreeing.

An overwhelming majority of participants (70.65\%) -agree (28.25\%) or strongly agree (42.3\%) that social media should be included as an integral part of foreign language curricula. These percentages are very close to those presented previously. Participants see the necessity and importance of subscribing to pages/accounts/channels that specialize in teaching foreign languages because of their benefits with $43 \%$ agreeing and $32 \%$ strongly agreeing to the statement relating to the subscription to the pages/accounts/channels.

Since the meanings and functions are largely dependent on sociocultural data, linguistic knowledge is an integral part of sociocultural knowledge. It is important to understand that the social system of life cultural values, ideologies, knowledge structures and interpretations are acquired through the linguistic mediator. This explains the attempt to adapt the tools of social media to serve and achieve this by developing and enhancing the language skills of individuals. As observed herein, $75.8 \%$ (47.3\%-agree and 28.5\%-strongly agree) supported the feasibility of social media in developing their speaking skills. According to Wolfgang (1986, p.28-30), in the Interlanguage Theory, a language learner must use his or her potential whatever the circumstances in which that foreign language is learned. We aim to use language as a communicative tool in life, which applies to what happens in social media or to use language by speaking it, listening to it to practice the same language, and learning more until it is mastered.

\section{H. Reasons and Motivations for Learning Languages}

Participants overwhelmingly (48\%) hinted that they were learning a new language in order to communicate better in day-to-day life. It was obvious in UAE because it hosts many nationalities as we mentioned above. Moreover, other respondents mentioned that they learn languages for a certain purpose like study, work, or to use it when traveling abroad (Figure 14).

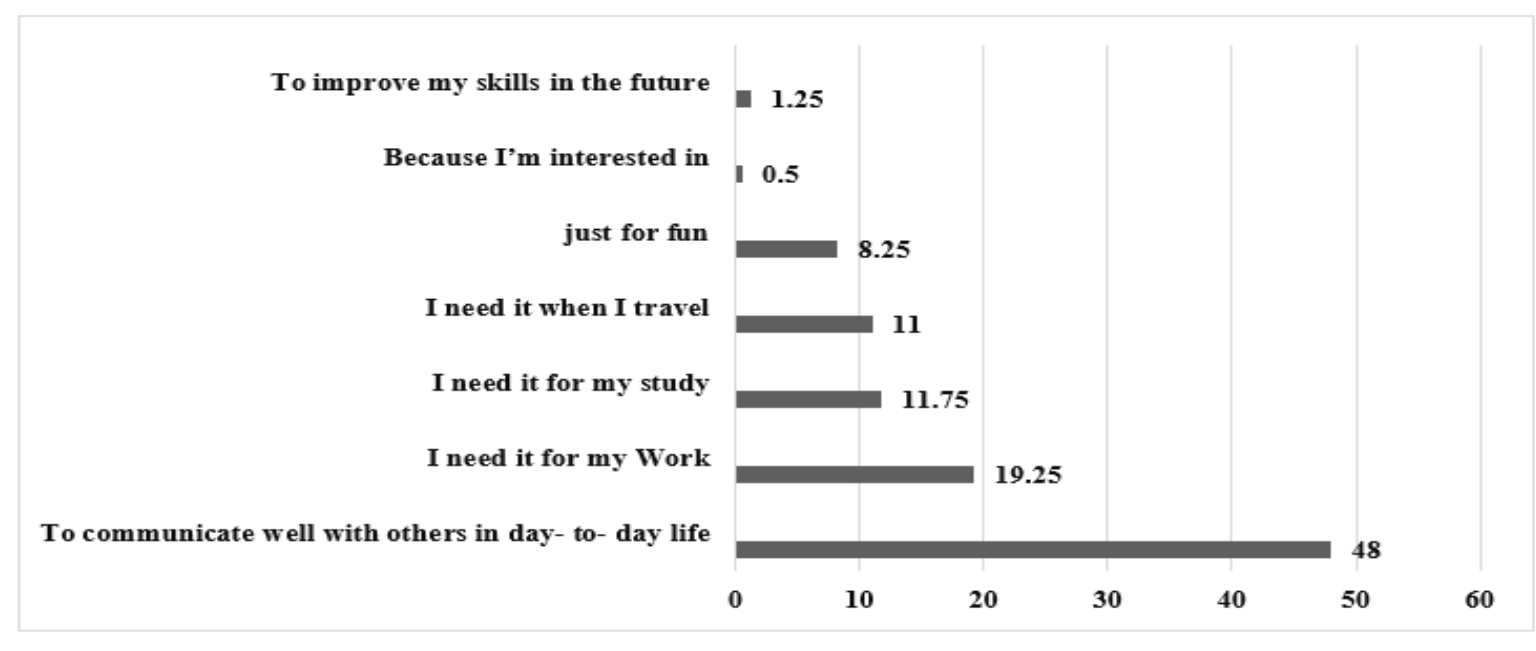

Figure-14. Participants' reasons for learning new languages. 


\section{DISCUSSION}

This study assessed and analyzed the usability, usefulness, and the impact of social media networks as a learning tool for Arab youth. It further determined the attitudes of Arab youth toward social media networks as a tool for learning foreign languages. Results revealed that Arab youth find social media useful for learning languages; they have embraced social media networks and used them as learning tools to learn language. It was further revealed that Arab youth have been using social media as learning tools for a period spanning several years demonstrating that they understand its usefulness as learning tools for learning language; especially because they feel comfortable during their experience on social media networks. Unsurprisingly, the results show that the favorite language for Arab youth in communication through social media networks was the Arabic language. This appeared reasonable considering that Arabic is the native language of these youth, but the rest of the participants' $(35.75 \%)$ emphasize that they prefer to communicate with others in English or French, or even a mix between Arabic and English languages through "Franco Arab". The results also confirmed that Arab youth predominantly use Facebook, snap chat, and Instagram, as favorite social media networking sites for them.

These results are in conformity with other studies investigated within the context of Arab countries (Aifan, 2015; Alaa, 2015; Alfak \& Alfaki, 2014; Anderson, 2007; Caverlee \& Webb, 2008; El-Emran \& Al-Qaysi, 2017; Mc Dermott, 2013; Spaniol et al., 2009; Zyl, 2009).

Results of the present study suggest that through social media platforms, learners also meet old and new friends and thus get new information that helps increase their ability to learn and acquire a new language. Results of this study also emphasize the importance of integrating multiple social media tools notably Facebook and YouTube to Arab learners of foreign languages to acquire the second language. Such integration would help enhance language learning as well as learners' experience.

Funding: This study received no specific financial support.

Competing Interests: The authors declare that they have no competing interests

Acknowledgement: All authors contributed equally to the conception and design of the study.

\section{REFERENCES}

Aifan, A. H. (2015). Saudi students' attitudes toward using social media to support learning. Doctoral Dissertation.

Alaa, I. K. (2015). How undergraduate female students in the Kingdom of Saudi Arabia perceive social media as a learning tool. Electronic Theses and Dissertations. 5290.

Alfak, I. M., \& Alfaki, I. M. (2014). Towards a digital world: Using social networks to promote learner's language. American International Journal of Contemporary Research, 4(10), 105-113.

Anderson, P. (2007). What is web 2.0? Ideas, technologies and implications for education. JISC Technology and Standards Watch. Retrieved from http://www.jisc.ac.uk/media/documents/techwatch/tsw0701b.pdf. [Accessed 18th March 2018]

Baird, D. E., \& Fisher, M. (2005). Neomillennial user experience design strategies: Utilizing social networking media to support "always on" learning styles. Journal of Educational Technology Systems, 34(1), 5-32. Available at: https://doi.org/10.2190/6WMW-47Lo-M81Q-12G1.

Baruah, T. D. (2012). Effectiveness of social media as a tool of communication and its potential for technology enabled connections: A micro-level study. International Journal of Scientific and Research Publications, 2(5), 1-10.

Caverlee, J., \& Webb, S. (2008). A large-scale study of myspace: Observations and implications for online Social Networks. In ICWSM.

Chiu, C., Krauss, R. M., Lam, H. Y., \& Tong, J. Y. (1995). Language, communication and cognition: A post-Whorfian approach. Manuscript under review. Opayemi, A.S., Oyeleke, J.T., Popoola, A.B., Oguntayo, R., Psychology of Language: Communication and Social Behaviour. Retrieved from https:// www.researchgate.net. 
El-Emran, M., \& Al-Qaysi, N. (2017). Code-switching usage in social media: A case study from Oman. International Journal of Information Technology and Language Studies, 1(1), 25-38.

Fuchs, C., Hofkirchner, W., Schafranek, M., Raffl, C., Sandoval, M., \& Bichler, R. (2010). Theoretical foundations of the web: Cognition, communication, and co-operation. Towards an Understanding of Web 1.0, 2.0, 3.O. Future Internet, 2(1), 41-59.

Griesemer, J. A. (2012). Using social media to enhance students' learning experiences. Quality Approaches in Higher Education, $3(1), 8-11$.

Mc Dermott, G. (2013). The role of social media in foreign language teaching: A case study for French. Research and Teaching Practices in Specialized Languages. Apliut notebooks, 32(2), 141-157.

Megan, S. P., \& Liu, M. (2010). Learning a language with Web 2.0: Exploring the use of social networking features of foreign language learning websites. CALICO Journal, 27(2), 233-259.

Mondahl, M., Rasmussen, J., \& Razmerita, L. (2009). Web 2.0 Applications, collaboration and cognitive processes in case-based foreign language learning. In M. Lytras (Ed.), 2nd World Summit on the Knowledge Society,Crete, Greece, Computer Science (Vol. LNAI 5736, pp. 98-107). Berlin Heidelberg: Springer-Verlag.

Mondahl, M., \& Razmerita, L. (2014). Social media, collaboration and social learning--A case-study of foreign language learning. Electronic Journal of E-learning, 12(4), 339-352.

Spaniol, M., Li, Q., Klamma, R., \& Lau, R. W. H. (2009). Advances in web based learning (Vol. 5686). Berlin: Heidelberg: Springer Berlin Heidelberg.

Stevenson, M. P., \& Liu, M. (2013). Learning a language with Web 2.0: Exploring the use of social networking features of foreign language learning websites. CALICO Journal, 27(2), 233-259.

Tosh, D., \& Werdmuller, B. (2004). Creation of a learning landscape: Weblogging and social networking in the context of eportfolios. Creation of a learning landscape. Retrieved from http://citeseerx.ist.psu.edu.

Zyl, A. S. V. (2009). The impact of social networking 2.0 on organizations. The Electronic Library, 27(6), 906-918. Available at: https://doi.org/10.1108/02640470911004020.

Views and opinions expressed in this article are the views and opinions of the author(s), International Journal of English Language and Literature Studies shall not be responsible or answerable for any loss, damage or liability etc. caused in relation to/arising out of the use of the content. 